\title{
Folic acid food fortification prevents inadequate folate intake among preschoolers from Ontario
}

\author{
Kathleen Hennessy-Priest ${ }^{1}$, Jill Mustard ${ }^{1}$, Heather Keller ${ }^{1}$, Lee Rysdale ${ }^{2}$, Joanne Beyers ${ }^{2}$, \\ Richard Goy ${ }^{1}$ and Janis Randall Simpson ${ }^{1, *}$ \\ 'Department of Family Relations and Applied Nutrition, University of Guelph, MACS Room 324, Guelph, \\ Ontario, Canada, NIG 2W1: ${ }^{2}$ Public Health Research, Education \& Development (PHRED) Program, Sudbury \& \\ District Health Unit, Sudbury, Ontario, Canada
}

Submitted 31 December 2007: Accepted 13 November 2008: First published online 6 February 2009

\begin{abstract}
Objective: Folic acid food fortification has successfully reduced neural tube defect-affected pregnancies across Canada. The effect of this uncontrolled public health intervention on folate intake among Canadian children is, however, unknown. Our objectives were to determine folic acid intake from food fortification and whether fortification promoted adequate folate intakes, and to describe folic acid-fortified food usage among Ontario preschoolers.

Design: Cross-sectional data were used from the NutriSTEP ${ }^{\mathrm{TM}}$ validation project with preschoolers recruited using convenience sampling. Mean daily total folate and folic acid intakes were estimated from $3 \mathrm{~d}$ food records, which included multivitamin supplement use. Comparisons were made to Dietary Reference Intakes, accounting for and excluding fortificant folic acid, to determine the prevalence of inadequate and excessive intakes.

Setting: Canada.

Subjects: Two hundred and fifty-four preschoolers (aged 3-5 years).

Results: All participants (130 girls, 124 boys) ate folic acid-fortified foods and 30\% ( $n$ 76) used folic acid-containing supplements. Mean (SE) fortificant folic acid intake was 83 (2) $\mu \mathrm{g} / \mathrm{d}$, which contributed $30 \%$ and $50 \%$ to total folate intake for supplement users and non-users, respectively. The prevalence of total folate intakes below the Estimated Average Requirement was $<1 \%$; however, excluding fortificant folic acid, the prevalence was $32 \%, 54 \%$ and $47 \%$ for 3-, 4 - and 5-yearolds, respectively. The overall prevalence of folic acid (fortificant and supplemental) intakes above the Tolerable Upper Intake Level was 2\% (7\% among supplement users).

Conclusions: Folic acid food fortification promotes dietary folate adequacy and did not appear to result in excessive folic acid intake unless folic acid-containing supplements were consumed.
\end{abstract}

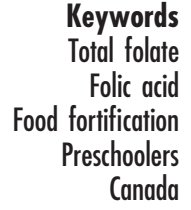

The Canadian Government mandated the fortification of white flour, enriched pasta and cornmeal with folic acid in November $1998^{(1)}$, in response to the weight of evidence for this vitamin's role in neural tube defect (NTD) risk reduction ${ }^{(2-4)}$. Folic acid is also added to a variety of foods, such as breakfast cereals and pre-cooked rice, on a voluntary basis ${ }^{(5,6)}$. The use of folic acid as a food fortificant in Canada is tightly controlled ${ }^{(5)}$ and aims to help women of childbearing age meet their periconceptional folic acid requirement of $400 \mu \mathrm{g} / \mathrm{d}^{(7)}$.

This public health policy has been highly effective in improving child health in Canada, as demonstrated by the significant reduction in NTD-affected pregnancies ${ }^{(8-12)}$. Furthermore, it has been positively associated with a significant decrease in neuroblastoma incidence among children in Ontario ${ }^{(13)}$. Positive effects related to folate nutriture have also been reported among adult Canadians ${ }^{(14-16)}$

Fortifying foods with folic acid is, however, an uncontrolled intervention, to which all Canadians, including children, are exposed. A wide range of folic acid-fortified foods are available ${ }^{(5,17)}$, most of which are folic acid in the Canadian food supply has undoubtedly increased since mandatory fortification and is estimated to be higher than targeted levels ${ }^{(18)}$. However, 10 years later, there remains a paucity of published data describing not only current dietary folate intake among Canadian regularly consumed by young children. The amount of 
preschoolers and how fortification and supplementation contribute to total intake, but also data describing their folic acid-fortified food usage. Data from the USA ${ }^{(19)}$ suggest that a considerable proportion of US children have folic acid intakes above the Tolerable Upper Intake Level (TUL), the highest average daily nutrient intake level likely to pose no risk of adverse health effects to almost all individuals in a specified life-stage group ${ }^{(20)}$. This prompts questions concerning folic acid intakes among Canadian children, since folic acid fortification regulations in Canada ${ }^{(5)}$ and the USA ${ }^{(21)}$ are rather similar. Furthermore, recently proposed Canadian food fortification regulatory amendments ${ }^{(22)}$ will, it is anticipated, increase the amount of folic acid in the food supply further. Data describing multivitamin/mineral supplement use among Canadian preschoolers are also lacking; however, in the USA as many as $46 \%$ of preschoolers are estimated to use such supplements ${ }^{(23)}$.

Our objectives therefore were to: (i) quantify current total dietary folate and folic acid intakes among a sample of Ontario preschoolers and determine whether fortification promoted adequate or excessive intakes; (ii) examine the contribution of folic acid food fortification and supplementation to total folate intake; and (iii) describe folic acid-fortified food consumption.

\section{Methods}

\section{Recruitment and subjects}

The present descriptive cross-sectional study used dietary and demographic data from the NutriSTEP ${ }^{\mathrm{TM}}$ validation study $^{(24)}$ and was approved by the University of Guelph Research Ethics Board. NutriSTEP ${ }^{\mathrm{TM}}$ is a community-based, parent-administered, preschooler nutrition risk screening tool, which has undergone extensive development. Children (aged 3-5 years) were eligible to participate in the original study ${ }^{(24)}$ if their parents possessed English or French writing and literacy skills at a grade 6 level, had lived in Canada for at least 5 years and gave written informed consent.

Participants were recruited from five areas across Ontario (Table 1). Convenience sampling from community locations including health screening fairs, child-care centres and other preschooler programmes (e.g. Ontario Early Years Centres) was used to maximize diversity in the sample. Incentives included a NutriSTEP ${ }^{\mathrm{TM}}$ measuring cup and two accompanying nutrition education resources $^{(25,26)}$, and participants were compensated for travel time and parking expenses.

\section{Data collection}

Data were collected between May 2005 and January 2006, by three purposely trained registered dietitians, using standardized data collection tools and procedures. Parents were trained in person to complete a food record over
Table 1 Demographic characteristics of Ontario preschoolers ( $n$ 254) and respondent parents

\begin{tabular}{|c|c|c|}
\hline Characteristic & $n$ & $\%$ \\
\hline \multicolumn{3}{|l|}{ Child's age } \\
\hline 3 years & 128 & 50 \\
\hline 4 years & 79 & 31 \\
\hline 5 years & 47 & 19 \\
\hline \multicolumn{3}{|l|}{ Child's gender } \\
\hline Male & 124 & 49 \\
\hline Female & 130 & 51 \\
\hline \multicolumn{3}{|l|}{ Residential location } \\
\hline York region & 107 & 42 \\
\hline London-Middlesex County & 77 & 30 \\
\hline $\begin{array}{l}\text { City of Greater Sudbury (urban and } \\
\text { rural Francophones) }\end{array}$ & 29 & 11 \\
\hline $\begin{array}{l}\text { Manitoulin Island (on- and off-reserve } \\
\text { First Nations) }\end{array}$ & 21 & 8 \\
\hline Guelph and Hamilton & 20 & 8 \\
\hline \multicolumn{3}{|l|}{ Parent gender ( $n$ 253) } \\
\hline Female & 237 & 94 \\
\hline Male & 16 & 6 \\
\hline \multicolumn{3}{|l|}{ Parent marital status ( $n$ 250) } \\
\hline Married/common law & 227 & 91 \\
\hline Single & 12 & 5 \\
\hline Widowed/separated/divorced & 11 & 4 \\
\hline \multicolumn{3}{|l|}{ Parent's highest education level ( $n$ 250) } \\
\hline Did not graduate high school & 28 & 11 \\
\hline Graduated high school & 19 & 4 \\
\hline Some college/university & 33 & 13 \\
\hline Graduated college/university & 179 & 72 \\
\hline \multicolumn{3}{|l|}{ Parental annual income } \\
\hline Less than CAN\$30000 & 27 & 11 \\
\hline CAN\$30 000-60000 & 45 & 18 \\
\hline Over CAN\$60000 & 138 & 54 \\
\hline Don't know & 44 & 17 \\
\hline \multicolumn{3}{|l|}{ Maternal country of birth ( $n$ 252) } \\
\hline Canada & 190 & 75 \\
\hline All other & 62 & 25 \\
\hline \multicolumn{3}{|l|}{ Maternal ethnicity ( $n$ 230) } \\
\hline Canadian, including First Nations & 118 & 51 \\
\hline All other & 112 & 49 \\
\hline
\end{tabular}

three consecutive days (including one weekend day) reporting any multivitamin supplements (including dosage) consumed. Household measures, measuring cups and spoons and manufacturers' food labels were used to help parents estimate food and beverage portion sizes. Brand names aided identification of folic acidfortified foods. Parents also self-completed an eight-item standardized demographic questionnaire adapted from Statistics Canada ${ }^{(27)}$.

\section{Dietary analyses}

Nutrient intakes were estimated from the food records using the CANDAT Nutrient Calculation System version 7.0 (Godin London Inc., London, ON, Canada) and the 2005 Canadian Nutrient File (CNF; Health Canada, Ottawa, ON, Canada), which analyses total folate (in both $\mu \mathrm{g}$ DFE (dietary folate equivalents) and $\mu \mathrm{g}$ ), folic acid and naturally occurring folate. Of 269 participant food records returned, 94\% ( $n$ 254) were analysed. Those excluded were illegible or poorly detailed $(n 4)$ or from participants for whom other NutriSTEP ${ }^{\mathrm{TM}}$ data sources 
were incomplete ( $n$ 11). Coding rules were developed to manage missing data describing brand names, preparation methods, food descriptions and portion sizes, for which Canada's Food Guide to Healthy Eating for Preschoolers $^{(28)}$ was used. Foods, beverages and supplements containing folic acid were identified as such using current fortification regulations ${ }^{(5)}$, brand-specific product data from food manufacturers and retailers and by examining ingredient lists for added folic acid. With regard to ingested folic acid-fortified foods or supplements that were absent from the $\mathrm{CNF}^{(17)}$, total folate, naturally occurring folate and folic acid content were estimated from manufacturers' product data and fortification regulations ${ }^{(5)}$. Folic acid-fortified foods were categorized by food type, e.g. bread and bread-type products, and cold breakfast cereals and bars. Supplemental folic acid intake was estimated using consumption and dosage data from parents and from manufacturers' product composition data.

Dietary analyses were conducted for the entire study sample, for age-defined subgroups (3, 4 and 5 years of age) and according to whether or not multivitamin supplements were used. Actual nutrient intakes were statistically adjusted for intra-individual variation using the National Research Council method ${ }^{(20,29)}$, yielding usual mean daily nutrient intakes which were then compared with Dietary Reference Intakes (DRI) ${ }^{(7)}$. Since the nutrient intake data were not normally distributed, natural logarithm transformations were applied before making the adjustments for intra-individual variation. Usual daily total folate ( $\mu$ g DFE) and folic acid intakes for the entire sample, and by age, were calculated as follows: total naturally occurring dietary folate intake ( $\mu$ g DFE) (from unfortified and fortified foods) + [folic acid from fortified foods and supplements $(\mu \mathrm{g}) \times 1 \cdot 7]$, thereby accounting for the higher bioavailability of synthetic folic acid ingested with food compared with naturally occurring folate ${ }^{(7,30)}$. Folic acid includes folic acid from fortified food and multivitamin supplements.

The prevalences of inadequate and potentially excessive intakes of total folate and folic acid were determined using the EAR (Estimated Average Requirement) and the TUL cut-point methods, respectively ${ }^{(20)}$, while accounting for, and excluding, folic acid from food fortification. In addition, estimates of the prevalence above the TUL were estimated for regulatory overages of $150 \%$ and $200 \%{ }^{(22)}$.

The contributions made to total folate ( $\mu$ g DFE) intake by naturally occurring folate, fortificant folic acid and supplemental folic acid were determined for both users and non-users of multivitamin supplements for all ages combined (data analysis showed no significant differences in total dietary folate intake by age). The contributions (\%) made by folic acid-fortified foods, classified into nine different groups, to fortificant folic acid intake were also calculated.

\section{Statistical analyses}

Statistical analyses were conducted using the Statistical Package for the Social Sciences statistical software package version $12 \cdot 0 \cdot 2$ (SPSS Inc., Chicago, IL, USA). Statistical significance was accepted at $P<0 \cdot 05$. Significance levels quoted are two-sided. ANOVA $F$, Kruskal-Wallis $H$ and $\chi^{2}$ tests were used to examine differences between groups, such as those defined by age, for significance.

\section{Results}

The sample of 254 preschoolers ( $51 \%$ female, $n$ 130) was drawn from rural and urban communities across Ontario and their parents were ethnically diverse (Table 1).

Folic acid-fortified foods were eaten by all the participants, 95\% ( $n$ 241) of whom did so on all three days observed. A considerable variety of fortified foods were eaten, with a mean of $8 \cdot 3$ (SD $2 \cdot 8$; minimum 2 , maximum 17) different fortified foods (e.g. breads, bagels, cookies, pasta and breakfast cereals) being consumed per participant over the three days. Almost $80 \%$ ( $n$ 200) ate folic acid-fortified breakfast cereal and just under one-third (30\%, $n$ 76) used folic acid-containing supplements, neither varying significantly with age.

As shown in Table 2, overall, mean (SE) total folate intake for the study population was 336 (8) $\mu \mathrm{g}$ DFE/d. There were no significant differences among age groups for either total folate $(P=0 \cdot 09)$ or folic acid $(P=0 \cdot 25)$ intake (Table 2 ). When folic acid from food fortification and supplementation were accounted for, only one participant had an inadequate ( $<$ EAR) total folate intake (Table 3); however, when fortificant folic acid was excluded the prevalence of inadequate total folate intakes was $32 \%, 54 \%$ and $47 \%$ among 3-, 4- and 5-year-olds, respectively.

The overall prevalence of total folic acid intakes (from food fortification and multivitamin supplements) above the TUL was $2 \%$ (2\% and $4 \%$ for 3 - and 5-year olds, respectively; Table 3). Of those children who did not use multivitamin supplements, all had total folic acid intakes below the TUL; however, $7 \%$ of the supplement users had total folic acid intakes in excess of the TUL with total folic acid intakes ranging from 366 to $583 \mu \mathrm{g} / \mathrm{d}$.

Based on an overage estimate of $150 \%$, there would be no increase in the prevalence of total folic acid intakes above the TUL, even for supplement users. However, an overage of $200 \%$ would increase the prevalence above the TUL to $4 \%$ (from $2 \%$ ) for the entire sample and to $12 \%$ (from 7\%) for supplement users.

Usual mean (sE) daily fortificant folic acid intake was 80 (3) $\mu \mathrm{g}$ and 85 (2) $\mu \mathrm{g}$ for supplement users and nonusers, respectively (Table 4) and 83 (2) $\mu \mathrm{g}$ for the entire sample. For supplement users, folic acid from fortified foods and supplements contributed 30\% and 39\%, 
Table 2 Usual daily total folate and folic acid intakes compared with the $\mathrm{DRI}{ }^{(7)}$ for Ontario $(n 254)$ preschoolers, by age

\begin{tabular}{|c|c|c|c|c|c|c|c|c|}
\hline \multirow[b]{2}{*}{ Age (years) } & \multirow[b]{2}{*}{ No. of subjects } & \multirow[b]{2}{*}{ Nutrient } & \multirow[b]{2}{*}{$\mathrm{EAR}^{*}(\mu \mathrm{g} \mathrm{DFE} / \mathrm{d})$} & \multirow[b]{2}{*}{ TULt $(\mu \mathrm{g} / \mathrm{d})$} & \multicolumn{4}{|c|}{ Adjusted $^{(29)}$ usual daily nutrient intake } \\
\hline & & & & & Mean & SE & Median & Minimum, maximum \\
\hline \multirow{2}{*}{$3-5$} & 254 & Total folateł & - & - & 336 & $7 \cdot 8$ & 314 & 145,1117 \\
\hline & & Folic acid§ & - & - & 114 & $4 \cdot 8$ & 96 & 18,583 \\
\hline \multirow[t]{2}{*}{3} & 128 & Total folate & 120 & & 321 & $10 \cdot 4$ & 310 & 145,1011 \\
\hline & & Folic acid & & 300 & 107 & $5 \cdot 8$ & 91 & 18,509 \\
\hline \multirow[t]{2}{*}{4} & 79 & Total folate & 160 & & 343 & $12 \cdot 1$ & 319 & 150,772 \\
\hline & & Folic acid & & 400 & 118 & $6 \cdot 6$ & 105 & 25,359 \\
\hline \multirow[t]{2}{*}{5} & 47 & Total folate & 160 & & 367 & $23 \cdot 6$ & 330 & 239,1117 \\
\hline & & Folic acid & & 400 & 126 & $14 \cdot 1$ & 99 & 44,583 \\
\hline
\end{tabular}

DRI, Dietary Reference Intakes; EAR, Estimated Average Requirement; DFE, dietary folate equivalents; TUL, Tolerable Upper Intake Level.

${ }^{*}$ EAR applies to total folate intake.

†TUL applies to synthetic folic acid only (from food fortification and supplementation).

$\ddagger$ Total folate ( $\mu \mathrm{g}$ DFE) intake includes all naturally occurring folate (from unfortified and fortified foods) and all folic acid from fortified foods and multivitamin supplements $((\mu \mathrm{g}) \times 1 \cdot 7)$, thereby accounting for the higher bioavailability of folic acid ingested with food compared with that of naturally occurring folate. $\S$ Folic acid $(\mu \mathrm{g})$ intake includes folic acid from fortified foods and multivitamin supplements.

Table 3 Prevalence of folate intakes less than the EAR and greater than the TUL by age, with and without fortification with folic acid, for a sample of Ontario ( $n$ 254) preschoolers

\begin{tabular}{|c|c|c|c|c|c|c|c|c|c|}
\hline \multirow[b]{3}{*}{ Age (years) } & \multirow[b]{3}{*}{ No. of subjects } & \multicolumn{4}{|c|}{ With folic acid fortification* } & \multicolumn{4}{|c|}{ Without folic acid fortificationt } \\
\hline & & \multicolumn{2}{|c|}{ Prevalence $<$ EAR } & \multicolumn{2}{|c|}{ Prevalence $>$ TUL $\ddagger$} & \multicolumn{2}{|c|}{ Prevalence $<$ EAR } & \multicolumn{2}{|c|}{ Prevalence $>$ TUL } \\
\hline & & $n$ & $\%$ & $n$ & $\%$ & $n$ & $\%$ & $n$ & $\%$ \\
\hline $3-5$ & 254 & 1 & $<0.1$ & 5 & $2 \cdot 0$ & 106 & $41 \cdot 7$ & 5 & $2 \cdot 0$ \\
\hline 3 & 128 & 0 & 0.0 & 3 & $2 \cdot 3$ & 41 & $32 \cdot 0$ & 3 & $2 \cdot 3$ \\
\hline 4 & 79 & 1 & $1 \cdot 2$ & 0 & 0.0 & 43 & $54 \cdot 4$ & 0 & 0.0 \\
\hline 5 & 47 & 0 & 0.0 & 2 & $4 \cdot 3$ & 22 & $46 \cdot 8$ & 2 & $4 \cdot 3$ \\
\hline
\end{tabular}

EAR, Estimated Average Requirement; TUL, Tolerable Upper Intake Level.

*Includes naturally occurring folate from food and folic acid from food fortification and supplements.

tIncludes naturally occurring folate from food and folic acid from supplements but not from food fortification.

‡TUL applies to synthetic folic acid only (from food fortification and supplementation).

Table 4 Usual folate intakes of users and non-users of supplements for a sample of Ontario $(n$ 254) preschoolers

\begin{tabular}{|c|c|c|c|c|c|c|c|c|}
\hline & \multicolumn{4}{|c|}{ Supplement users ( $n$ 76) } & \multicolumn{4}{|c|}{ Supplement non-users ( $n$ 178) } \\
\hline & Mean & SE & Median & P25, P75 & Mean & SE & Median & P25, P75 \\
\hline Naturally-occurring dietary folate $(\mu \mathrm{g} / \mathrm{d})^{\star}(\mathrm{A})$ & 133 & 3.9 & 124 & 107,156 & 135 & $2 \cdot 5$ & 130 & 11,160 \\
\hline Folic acid from fortified food $(\mu \mathrm{g} / \mathrm{d})^{*}(B)$ & 80 & $2 \cdot 5$ & 79 & 50,117 & 85 & $1 \cdot 8$ & 82 & 62,133 \\
\hline Supplemental folic acid $(\mu \mathrm{g} / \mathrm{d})+(\mathrm{C})$ & 103 & $10 \cdot 9$ & 100 & 33,100 & 0 & 0 & 0 & 0 \\
\hline Total dietary and supplemental folate $(\mu \mathrm{g} D F E / d) \ddagger$ & 444 & $18 \cdot 3$ & 411 & 369,481 & 280 & $7 \cdot 5$ & 281 & 245,325 \\
\hline
\end{tabular}

P25, 25th percentile; P75, 75th percentile.

*Values are usual (adjusted).

+Values are unadjusted.

$\ddagger$ Calculated as: $A+[(B+C) \times 1 \cdot 7]$ (assuming supplemental folic acid was consumed with food, such as at breakfast).

respectively, to total folate intake, while among non-users of supplements, folic acid from fortified food contributed $50 \%$ to total folate intake. Of the nine groups of folic acidfortified foods consumed (Fig. 1), the bread and pasta groups contributed most to folic acid intake (mean (SD) 36 (24) \% and 26 (25) \%, respectively). No significant differences existed on the basis of age except for hot breakfast cereal. Four-year-olds consumed significantly $\left(\chi^{2}=11.09, \mathrm{df}=2, P=0.004\right)$ more folic acid from hot cereal than 3- or 5-year-olds; however, hot cereal was not an important source for any age group (Fig. 1).

\section{Discussion}

In what we believe to be the first study of its kind involving Canadian children, we have shown that the policy of fortifying the food supply with folic acid, at current regulatory levels ${ }^{(5)}$, improved the dietary folate intake among these preschoolers and played an important role in preventing folate inadequacy in one-third of the 3-year-olds and approximately half of the 4- and 5-year-olds studied. Indeed, folate was not a nutrient of concern for this group of preschoolers, with all but 


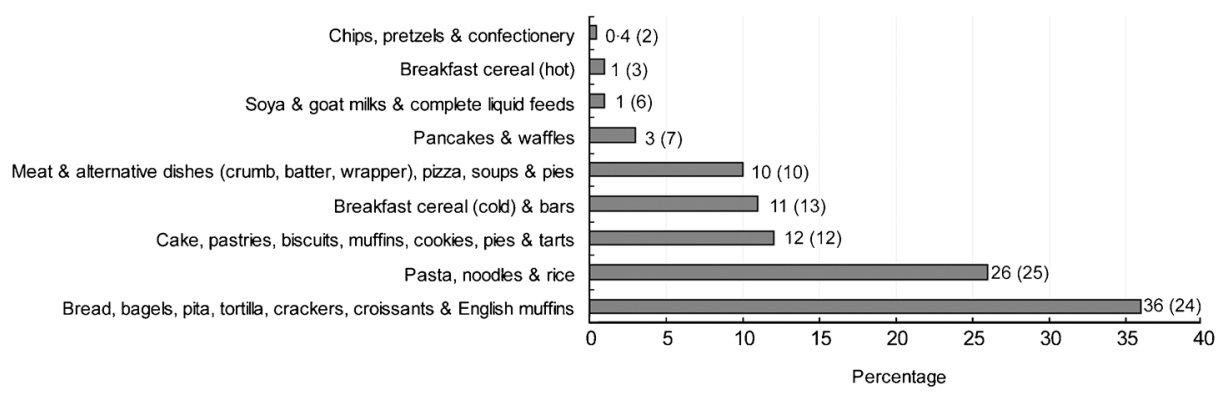

Fig. 1 Percentage contribution (SD) to fortificant folic acid intake made by specified folic acid-fortified foods, by group, in Ontario preschoolers ( $n$ 254)

one child having a total folate intake that exceeded the EAR.

Our overall estimate for total folate intake (336 DFE $\mu \mathrm{g} / \mathrm{d}$ ) is higher than that recently reported from the Canadian Community Health Survey (CCHS) Cycle $2 \cdot 2$ (245 and $266 \mu \mathrm{g}$ DFE/d among food-secure and -insecure 1-3-year-olds, respectively) ${ }^{(31)}$ and among Quebec preschoolers $^{(32)}$ (256 and $283 \mu \mathrm{g}$ DFE/d for girls and boys, respectively), as we accounted for supplemental folate as well, whereas these other studies did not. Our estimate for total folate intake among those preschoolers who did not use multivitamin supplements $(280 \mu \mathrm{g} \mathrm{DFE} / \mathrm{d})$ is comparable with both the $\mathrm{CCHS}^{(31)}$ and the Quebec ${ }^{(32)}$ data. Our overall estimate for total folate intake is also considerably lower than that reported for 1- to 5-year-old US children ${ }^{(19)}$ (548 and $533 \mu \mathrm{g}$ DFE/d from the third National Health and Nutrition Examination Survey (NHANES III) and the Continuing Survey of Food Intake by Individuals 1994-96 (CSFII), respectively) whose multivitamin supplement use was also accounted for. Reasons for this discrepancy may likely include sampling and dietary analytical differences, but it is primarily believed to be due to fortification regulatory differences between Canada and the USA. For example, considerably higher levels of breakfast cereal fortification are currently permitted in the $\mathrm{USA}^{(21)}$ (up to $400 \mu \mathrm{g} /$ serving) relative to Canada $^{(5)}(60 \mu \mathrm{g} / 100 \mathrm{~g}$ (2-3 servings)).

Considering all 254 preschoolers, overall usual mean daily total folic acid intakes, from fortified foods and supplements, were at most only one-third of the TUL, depending on age (Table 1), despite all of these Canadian children being folic acid-fortified food consumers. In addition, the prevalence of total folic acid intakes above the TUL was low (Table 2); even among those preschoolers who used multivitamin supplements, only $7 \%$ had excessive folic acid intakes. These findings also contrast with US data ${ }^{(19)}$ that suggest a high prevalence of folic acid intakes in excess of the TUL (21\% and 19\% of 1-3-year-olds and $16 \%$ and $32 \%$ of $4-8$-year-olds from NHANES III and CSFII, respectively) exists among American preschoolers.

Working on the assumption that enriched cereal-grain products would be fortified in accordance with regulatory requirements, it was originally predicted that the US folic acid fortification programme, on which the Canadian intervention is based, would add an average of $100 \mu \mathrm{g}$ folic acid/d to the folate intakes of adults ${ }^{(18,33,34)}$ including women of childbearing age. Reports ${ }^{(33,35)}$ suggest, however, that average fortificant folic acid intakes among US adults have increased by approximately twice that which was predicted. Based on changes in serum folate concentrations in Canadian women, Quinlivan and Gregory $^{(18)}$ estimated that Canadian folic acid fortification may have increased folic acid consumption by $150 \%$. As far as we are aware, no specific projections were made enumerating the likely impact of folic acid food fortification on folate intakes among young children. In the present study, irrespective of whether a child was a multivitamin supplements user or not, usual mean daily intake of fortificant folic acid, at mandated levels, was determined to be $83 \mu \mathrm{g}$. This would appear to be consistent with the level of intake that was originally predicted for adult women, taking into account the lower energy intakes among preschoolers compared with women.

The universal consumption of a considerable variety of folic acid-fortified foods by these preschoolers is indicative of the staple nature of many fortified foods (for example, white bread, enriched pasta and other products made with enriched white flour) in the diet of Canadian preschoolers. It is also indicative of the extent to which folic acid-fortified foods are pervasive throughout the Canadian food supply. Indeed, fortificant folic acid, at mandated levels, contributed substantially to the total folate intake of these preschoolers, making up on average one-third to one-half of total folate intake among the supplement users and non-users, respectively.

The present study has many strengths which include our having: (i) accounted for folate consumed from all potential dietary sources including food fortification (both mandatory and voluntary) and multivitamin supplements; (ii) used a rigorous process for prioritizing the use of brand-specific, rather than generic, food product nutritional composition data, thereby minimizing the use of substitutions during dietary analysis; (iii) reported folate intakes as $\mu \mathrm{g}$ DFE, thereby accounting for differences in bioavailability of naturally occurring folate and synthetic 
folic acid; and (iv) using estimated $3 \mathrm{~d}$ food records completed by parents and primary caregivers, which are reported to be not only reliable and valid at the group level among this population ${ }^{(36)}$ and to limit parental burden, but also enabled adjustment of nutrient intake data for intraindividual variation, yielding estimates of usual nutrient intake, as recommended ${ }^{(20,29)}$. In addition, although this was a convenience sample it was nevertheless socioeconomically, educationally, ethnically, culturally and geographically considerably diverse, representing both Canadian-born (including Francophone and First Nations) and immigrant families. On the other hand, this convenience sample may have been biased as a high proportion $(72 \%)$ of the parents had graduated from college or university compared with just $34 \%$ of Canadians ${ }^{(37)}$. In other respects, however, this convenience sample was similar to the Canadian population in terms of income (in 2006, $15 \%$ and $56 \%$ of Canadians had incomes less than CAN\$30000 and more than CAN\$60000, respectively) ${ }^{(38)}$ and immigration status (20\% of Canadians are immigrants) ${ }^{(39)}$. Interestingly, recent data from the 2004 $\mathrm{CCHS}^{(31)}$ demonstrated that mean daily folate intakes are not significantly different among young children from food-secure and food-insecure households; therefore, the results would not likely have been different with a more diverse socio-economic sample.

Some limitations affecting these dietary analyses are, however, also noteworthy. First, CNF data assume ${ }^{(40)}$ that the addition of folic acid to food is consistent with fortification regulations ${ }^{(5)}$. In practice, however, manufacturers' overages are common and can be considerable ${ }^{(41,42)}$. Indeed the actual folate content of the Canadian food supply is currently unknown, prompting researchers ${ }^{(43)}$ to suggest that levels at which folic acid is actually added to fortified foods be determined and continually monitored, a view with which we agree. Second, the percentage of foods for which complete CNF data for folate, DFE, folic acid and naturally occurring folate existed, while high $(87 \cdot 3-95 \cdot 5 \%)^{(40)}$, indicated the database was nevertheless incomplete. Third, food record coding rules were needed in order to manage some incomplete data in some of the food records. Given these limitations, our estimates for the folate and folic acid intakes of these preschoolers likely underestimate their actual value.

Proposed regulatory amendments ${ }^{(22)}$ to expand discretionary food fortification using folic acid (among other nutrients) and to permit higher amounts of folic acid to be added to breakfast cereals and enriched rice are expected to increase the availability of folic acid-fortified foods and raise folic acid consumption by Canadians further. These amendments aim, in part, to facilitate greater trade harmonization with the USA by reducing existing differences between Canadian ${ }^{(5)}$ and US $^{(21)}$ food fortification regulations. We have demonstrated that at current regulatory levels ${ }^{(5)}$, a proportion of this sample of preschoolers (albeit a relatively small one) had a mean daily total folic acid intake that was above the TUL. Based on the limitations affecting our dietary analyses and the possibility of overages in fortification, we believe that we have likely underestimated the true prevalence of excessive folic acid intakes. To attain this true prevalence would require composite diet analysis, which is resource-intensive and not without its limitations. The prevalence of excessive folic acid intakes among US preschoolers is reported to be substantial ${ }^{(19)}$ and recent US data ${ }^{(44)}$ confirm significant post-mandatory fortification increases in mean serum and erythrocyte folate concentrations and in the prevalence of high serum folate concentrations among young American children. It is our opinion that were the proposed regulatory amendments concerning folic acid ${ }^{(22)}$ to be implemented, a higher proportion of Canadian preschoolers would also likely have excessive folic acid intakes over and above the TUL, particularly if multivitamin supplements are also being used. Canadian children are frequent consumers of breakfast cereals as shown by our sample in which $80 \%$ of the children ate folic acid-fortified breakfast cereals. The proposed increase in the folic acid content of fortified breakfast cereals is potentially substantial: manufacturers would be permitted to add between 20 and $200 \mu \mathrm{g}$ folic acid per reference amount of cereal (i.e. 15-55 g cereal depending on cereal type) ${ }^{(22)}$, whereas currently just $60 \mu \mathrm{g}$ of folic acid are permitted per $100 \mathrm{~g}$ of cereal (or 2-3 servings) ${ }^{(5)}$. It should be remembered that the effects of lifelong exposure to large amounts of synthetic folic acid are, at present, unknown, while evidence is also emerging to suggest that folate has a dual effect in human carcinogenesis, protecting against cancer initiation but also facilitating progression and growth of pre-neoplastic cells $^{(45)}$. If implemented, the impact of these Canadian regulatory changes on the folic acid intake and folate status of Canadian children, of all ages, will undoubtedly require timely and thorough evaluation. While data pertaining to folate intake and status are being collected as part of the current Canadian Health Measures Survey, unfortunately no data are being collected from children younger than 6 years of age.

We were particularly interested in our observation that several of the paediatric multivitamin supplements used by these preschoolers contained $300-400 \mu \mathrm{g}$ of folic acid per daily dose, an amount equivalent to the TUL for 1-3- and 4-8-year-olds, respectively ${ }^{(7)}$. Approximately onethird of the preschoolers studied used a folic acid-containing supplement and almost $10 \%$ of these supplement-using preschoolers consumed multivitamin products that contained these higher levels of folic acid. Health-care professionals and parents alike need to be aware of these supplements; if taken regularly in addition to folic acidfortified foods, they certainly give rise to the likelihood of raising a child's usual folic acid intake beyond the current TUL. Indeed, all of those children in our study group who had total folic acid intakes above the TUL were 
consumers of multivitamin supplements containing $300 \mu \mathrm{g}$ or more of folic acid.

\section{Conclusion}

Current regulatory levels of folic acid fortification ${ }^{(5)}$ successfully promoted dietary folate intake to adequate levels and contributed to excessive folic acid intakes only in a small proportion of children who were concurrently using folic acid-containing multivitamin supplements with $300 \mu \mathrm{g}$ or more of folic acid. Thus we have demonstrated that the benefits of Canadian folic acid food fortification policy, in relation to child health, extend beyond the prevention of NTD.

\section{Acknowledgements}

Sources of funding: The study was supported by the Canadian Institutes for Health Research (Institute of Population and Public Health and Institute of Nutrition, Metabolism and Diabetes). Conflict of interest declaration: None declared. Authorship responsibilities: J.R.S., H.K., L.R. and J.B. obtained funding for the original study from which data were used. K.H.P., J.R.S. and H.K. developed the research idea, and planned and designed the study. J.R.S. and H.K. provided critical feedback on all phases of the study. Data collection was managed and coordinated by L.R. K.H.P. and J.M. were responsible for data entry. K.H.P. conducted dietary and statistical analysis with statistical support from R.G. K.H.P. drafted the manuscript and all authors contributed to its revision and approval. Acknowledgements: We are especially grateful to the parents and their preschoolers who participated in this study. We thank Sandra Juutilainen, Lorianne Maclean and Suzanne Lamoureux for collecting the data. For data entry we thank Alissa Palangio, and for dietary data entry we thank Michelle Saraiva, Lindsay Zalot and Yian Yian Dam.

\section{References}

1. Government of Canada (2003) Regulatory Impact Analysis Statement SOR/98-550. Canada Gazette 132, 3029-3033.

2. Medical Research Council Vitamin Study Research Group (1991) Prevention of neural tube defects: results of the Medical Research Council vitamin study. Lancet 338, 131-137.

3. Czeizel AE \& Dudas I (1992) Prevention of the first occurrence of neural-tube defects by periconceptional vitamin supplementation. New Engl J Med 327, 1832-1835.

4. Lumley J, Watson L, Watson M \& Bower C (2001) Periconceptional supplementation with folate and/or multivitamins for preventing neural tube defects. Cochrane Database Syst Rev issue 3, CD001056.

5. Health Canada (2005) Consolidation of the Food and Drugs Act and the Food and Drug Regulations. Ottawa, ON: Health Canada; available at http://www.hc-sc.gc.ca/fn-an/ legislation/acts-lois/fda-lad/index_e.html
6. Canadian Food Inspection Agency (2003) Guide to Food Labelling and Advertising. Chapter 7, Annex 7-1: Foods to which vitamins, mineral nutrients and amino acids may or must be added. http://www.inspection.gc.ca/english/fssa/ labeti/guide/ch7-1e.shtml (accessed December 20008).

7. Food and Nutrition Board, Institute of Medicine (1998) Folate. In Dietary Reference Intakes for Thiamin, Riboflavin, Niacin, Vitamin $B_{6}$, Folate, Vitamin $B_{12}$, Pantothenic Acid, Biotin, and Choline, pp. 196-305. Washington, DC: National Academy Press.

8. De Wals P, Tairou F, Van Allen MI et al. (2007) Reduction in neural-tube defects after folic acid fortification in Canada. $N$ Engl J Med 357, 135-142.

9. Liu S, West R, Randell E, Longerich L, Steel O'Connor K, Scott H, Crowley M, Lam A, Prabhakaran V \& McCourt C (2004) A comprehensive evaluation of food fortification with folic acid for the primary prevention of neural tube defects. BMC Pregnancy Childbirth 4, 20-29; available at http://www.biomedcentral.com/content/pdf/1471-2393-420.pdf

10. De Wals P, Rusen ID, Lee NS, Morin P \& Niyonsenga T (2003) Trend in prevalence of neural tube defects in Quebec. Birth Defects Res A Clin Mol Teratol 67, 919-923.

11. Ray JG, Meier C, Vermeulen MJ, Boss S, Wyatt PR \& Cole DE (2002) Association of neural tube defects and folic acid food fortification in Canada. Lancet 360, 2047-2048.

12. Persad VL, Van den Hof MC, Dubé JM \& Zimmer P (2002) Incidence of open neural tube defects in Nova Scotia after folic acid fortification. Can Med Assoc J 167, 241-245.

13. French AE, Grant R, Weitzman S, Ray JG, Vermeulen MJ, Sung L, Greenberg M \& Koren G (2003) Folic acid food fortification is associated with a decline in neuroblastoma. Clin Pharmacol Ther 74, 288-294.

14. Ray JG, Vermeulen MJ, Boss SC \& Cole DEC (2002) Declining rate of folate insufficiency among adults following increased folic acid food fortification in Canada. Can J Public Health 93, 249-253.

15. Ray JG, Vermeulen MJ, Boss SC \& Cole DEC (2002) Increased red cell folate concentrations in women of reproductive age after Canadian folic acid food fortification. Epidemiology 13, 238-240.

16. Ray JG, Vermeulen MJ, Langman LJ, Boss SC \& Cole DEC (2003) Persistence of vitamin $B_{12}$ insufficiency among elderly women after folic acid food fortification. Clin Biochem 36, 387-391.

17. Health Canada (2005) Canadian Nutrient File. Ottawa, ON: Health Canada.

18. Quinlivan EP \& Gregory JF (2003) The impact of food fortification on folic acid in Canada. Can J Public Health 94, 154.

19. Lewis CJ, Crane NT, Wilson DB \& Yetley EA (1999) Estimated folate intakes: data updated to reflect food fortification, increased bioavailability, and dietary supplement use. Am J Clin Nutr 70, 198-207.

20. Food and Nutrition Board, Institute of Medicine (2000) Dietary Reference Intakes: Applications in Dietary Assessment. Washington, DC: National Academy Press.

21. Department of Health and Human Services, Food and Drug Administration (1996) Food standards; amendment of standards of identity for enriched grain products to require addition of folic acid, final rule. Fed Regist $\mathbf{6 1}$, 8781-8797; available at http://www.cfsan.fda.gov/ lrd/ fr96305b.html

22. Health Canada (2005) Addition of Vitamins and Minerals to Foods: Proposed Policy and Implementation Plans. Ottawa, ON: Health Canada; available at http://www.hc-sc.gc. $\mathrm{ca} /$ fn-an/alt_formats/hpfb-dgpsa/pdf/nutrition/foritfication_ final_doc_e.pdf

23. Rock CL (2007) Multivitamin-mineral supplements: who uses them? Am J Clin Nutr 85, Suppl., S277-S279. 
24. Randall Simpson J, Keller HH, Rysdale LA \& Beyers JE (2008) Nutrition Screening Tool for Every Preschooler (NutriSTEP ${ }^{\mathrm{TM}}$ ): validation and test-retest reliability of a parent-administered questionnaire assessing nutrition risk of preschoolers. Eur J Clin Nutr 62, 770-780.

25. Sudbury \& District Health Unit (2004) How to Build a Healthy Preschooler. Sudbury, ON: Sudbury \& District Health Unit; available at http://www.beststart.org/ resources/nutrition/pdf/Healthy_Preschooler_Sept_04.pdf

26. Sudbury \& District Health Unit (2004) The ABC's of Feeding Preschoolers. Sudbury, ON: Sudbury \& District Health Unit; available at http://www.beststart.org/resources/nutrition/ pdf/NutriStepABC_eng.pdf

27. Statistics Canada (2001) Canadian Community Health Survey (CCHS) Questionnaire for Cycle 1.1 (Sept 2000-Nov 2001). Ottawa, ON: Statistics Canada

28. Health Canada (1995) Canada's Food Guide to Healthy Eating: Focus on Preschoolers. Ottawa, ON: Minister of National Health and Welfare.

29. Food and Nutrition Board, Institute of Medicine (2003) Appendix E: Adjustment of observed intake data to estimate the distribution of usual intakes in a group. In Dietary Reference Intakes: Applications in Dietary Planning, pp. 196-208. Washington, DC: National Academy Press.

30. Suitor CW \& Bailey LB (2000) Dietary folate equivalents: interpretation and application. J Am Diet Assoc 100, 88-94.

31. Kirkpatrick SI \& Tarasuk V (2008) Food insecurity is associated with nutrient inadequacies among Canadian adults and adolescents. J Nutr 138, 604-612.

32. Institut de la Statistique du Québec (2005) Enquête de Nutrition auprès des Enfants Québécois de 4 ans. Québec, QC: Gouvernement du Québec; available at http://www. stat.gouv.qc.ca/publications/sante/nutrition4ans_pdf_an.htm

33. Quinlivan EP \& Gregory JF III (2003) Effect of food fortification on folic acid intake in the United States. $A m J$ Clin Nutr 77, 221-225.

34. Food and Drug Administration (1993) Food labeling: health claims and label statements: folate and neural tube defects. Fed Regist 58, 53254-53295.
35. Choumenkovitch SF, Selhub J, Wilson PWF, Rader JI, Rosenberg IH \& Jacques PF (2002) Folic acid from fortification in United States exceeds predictions. J Nutr 132, 2792-2798.

36. Trumble-Waddell JE, Campbell ML, Armstrong LM \& MacPherson BD (1998) Reliability and validity of the three-day estimated record of food intake provided by parents and caregivers of preschool children in dual-earner families. Can J Diet Pract Res 59, 83-89.

37. Statistics Canada (2004) Census of Population. Population 15 Years and Over by Highest Level of Schooling, by Province and Territory (2001 Census). Ottawa, ON: Statistics Canada; available at http://www40.statcan.ca/ 101/cst01/educ43a.htm

38. Statistics Canada (2007) Family Income, by Family Type. Ottawa, ON: Statistics Canada; available at http://www. 40.statcan.ca/101/cst01/famil106a.htm

39. Statistics Canada (2006) 2006 Census of Population. Ottawa, ON: Statistics Canada; available at http://www. 12.statcan.ca/english/census06/data/highlights/Immigration/ Table403.cfm? Lang $=\mathrm{E} \& \mathrm{~T}=403 \& \mathrm{GH}=4 \& \mathrm{SC}=1 \& \mathrm{~S}=99 \& \mathrm{O}=\mathrm{A}$

40. Health Canada (2005) Canadian Nutrient File Users' Guide. Ottawa, ON: Health Canada.

41. Rader JI, Weaver CM \& Angyal G (2000) Total folate in enriched cereal-grain products in the United States following fortification. Food Chem 70, 275-289.

42. Whittaker P, Tufaro PR \& Rader JI (2001) Iron and folate in fortified cereals. I Am Coll Nutr 20, 247-254.

43. Sherwood KL, Houghton LA, Tarasuk V \& O'Connor DL (2006) One third of pregnant and lactating women may not be meeting their folate requirements from diet alone based on mandated levels of folic acid fortification. J Nutr 136, 2820-2826.

44. Pfeiffer CM, Caudhill SP, Gunter EW, Osterloh J \& Sampson EJ (2005) Biochemical indicators of B vitamin status in the US population after folic acid fortification: results from the National Health and Nutrition Examination Survey 1999-2000. Am J Clin Nutr 82, 442-450.

45. Smith AD, Kim Y-I \& Refsum H (2008) Is folic acid good for everyone? Am J Clin Nutr 87, 517-533. 